\title{
Optimal allocation of fuel and energy resources in the complex blast-furnace plants
}

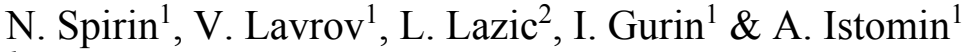 \\ ${ }^{1}$ Department of Metallurgy, Ural Federal University, Russia \\ ${ }^{2}$ University of Zagreb, Croatia
}

\begin{abstract}
The paper presents the model of optimal allocation of power resources in a blast furnace taking into account the change of smelting parameters. The optimization model allows to predict parameters of injected fuel on separate (at individual, in certain) blast furnaces in various technological situations. At problem formulation and task solution, the model considers the static characteristics describing the influence of changes of melting conditions on overall economic indicators of furnaces, the mathematical description external and internal limitations on operation of some blast furnaces and blast-furnace plant generally. Informational-modelling system optimization of allocation of natural gas in a blast-furnace plant was developed on the presented model. This model includes: input and adjustment of data; calculation module; optimization; output and the assaying of results. The results of comparative assaying of allocation of natural gas on the basis of operation data of the blast-furnace plant of OJSC "Magnitogorsk Iron and Steel Works" are achieved. Analysis of the results shows that the optimization model of joint distribution of natural gas and oxygen allows to use effectively the available fuel and energy resources, taking account the technological limitations in the work of individual furnaces as well as a plant in general.

Keywords: blast furnace production, optimization, mathematical modeling, distribution of energy resources, melting parameters.
\end{abstract}

\section{Introduction}

At the present time each metallurgical company should solve independently questions of optimization of a charge composition including the economic 
criteria, to estimate rationality of usage of various fuel and energy resources, to define management strategy of complex metallurgical aggregates. The special place in this complex of operations of reception of metal products is taken away to domain repartition as to the most power-intensive and difficult on which fraction it is necessary to $50 \%$ of fuel used in iron and steel industry. According to forecast prices for coke, finely pulverized coal fuel, natural gas will continue to grow in the nearest and long-term perspective. For a given overall consumption of these resources for the blast-furnace plant is advisable to have an operative technique of estimation of usage efficiency of fuel and energy resources for separate blast furnaces and to carry out an optimal allocation. This task is actual for the large blast-furnace plants involving to 10 blast furnaces, that smelting to 30 thousand tons pig-iron in a day for what it is used about 45 thousand tons iron-ore materials, 13 thousand tons of coke, 3.5 million $\mathrm{m}^{3}$ technological oxygen, to 4.0 million $\mathrm{m}^{3}$ natural gas.

Efficiency of application of combined blow is defined by factors of heat power, technological, economic character and external conditions. Presence of many factors and the criteria defining efficiency of usage of combined blow, and also limitations on expenditures of fuel and energy resources essentially complicates the task by definition of optimal blast characteristics at which reached best overall economic performance on separate blast furnaces, groups of furnaces and plant in generally. To solve this task it is possible only on the basis of wide usage of modern methods of mathematical modelling and developments on this ground of the automated systems of optimal allocation of power resources. Analysis of state issue on actual mathematical model used in practice of blast furnace technology shows that currently gap between potential of automation and real possibilities of used software is huge.

\section{The approach to construction of optimization model of allocation of natural gas in a blast-furnace plant}

At problem formulation and task solution of optimization of allocation of fuel and energy resources it is required not only studying the static characteristics describing influence of changes of melting conditions on overall economic indicators of furnaces, but also performance of the detailed analysis for mathematical description external and internal limitations. Besides, in practice it is necessary to estimate technical condition of furnace and equipment, size of expenditures of natural gas, quality of raw materials and other factors which are considered only by a method of expert estimations. As total quantity of fuel and energy resources (power of sources) is set, these guidelines should consider overall limit of the resources, allocated to blast-furnace plant.

The used approach is grounded on following positions: at rather small oscillations of parameters concerning the base values, it is expedient to use a principle of small deviations and to reduce an optimization problem to linear mathematical programming. The model developed earlier allowed to estimate on actual metrics of operation of separate blast furnaces an optimality of usage of natural gas at invariable on all blast furnaces parameters of mix material, 
temperature and humidity of a hot blow, an oxygen contents in blow at level of the base period that limited possibility of its practical application for prediction operating modes of separate furnaces and plant in generally [1-4].

Estimation of parameters of blast-furnace melting and calculation of coefficients linearization model performed with usage developed in Ural Federal University within the limits of the naturno-modelling approach of a balance model of a blast-furnace smelting operation which can be divided on two parts a model of base state and a prediction model $[1,5]$. The model of base (standard) state allows to estimate a state of each blast furnace and influence of input parameters on thermal, gas dynamic and slag modes of blast-furnace melting with usage of the actually accessible information about parameters of mix material, combined blow, a top smoke and melting products. The prediction model ground the results received by means of the model of base (standard) state, allows to estimate indicators of a blast-furnace smelting operation in the case of change of melting conditions.

\section{Model structure}

In figure 1 the structure of an advanced model of optimization of allocation of power resources in blast-furnace plant is presented at a modification of parameters of the melting, including following mainframes.

Base period. The estimation thermal, gas dynamic and slag operating modes of each of blast furnaces provides:

- Calculation of the complex of parameters thermal, gas dynamic and slag regimes of the blast-furnace fusion (about 30 parameters) [1, 6-8].

- Calculation of coefficients of agency:

- Parameters of a charge and air blast parameters on parameters thermal, gas dynamic and slag regimes of the blast-furnace melt;

- Parameters of a charge and air blast parameters on melting technical and economic indexes (a coke rate and productivity).

Forecast period. Feeding into of parameters of a charge and air blast parameters of each of blast furnaces:

- air blast parameters (temperature, humidity, an oxygen contents in air blast);

- chemical compound and properties iron-ore materials;

- charges and composition of fluxing stones;

- composition and properties of coke.

In a general view calculation of a modification of output parameters was defined under the following linear moulding box:

$$
\Delta y_{j i}=\left(x_{j i}^{f}-x_{j i}^{b}\right) \cdot k_{x_{j i}}^{b},
$$

where $\Delta y_{j i}-$ a modification of $i$ th design variable $y$ on $j$ th oven;

$x_{j i}^{f}$ - magnitude of parameter ${ }^{x_{i}}$ on $j$ th oven in forecast period; 


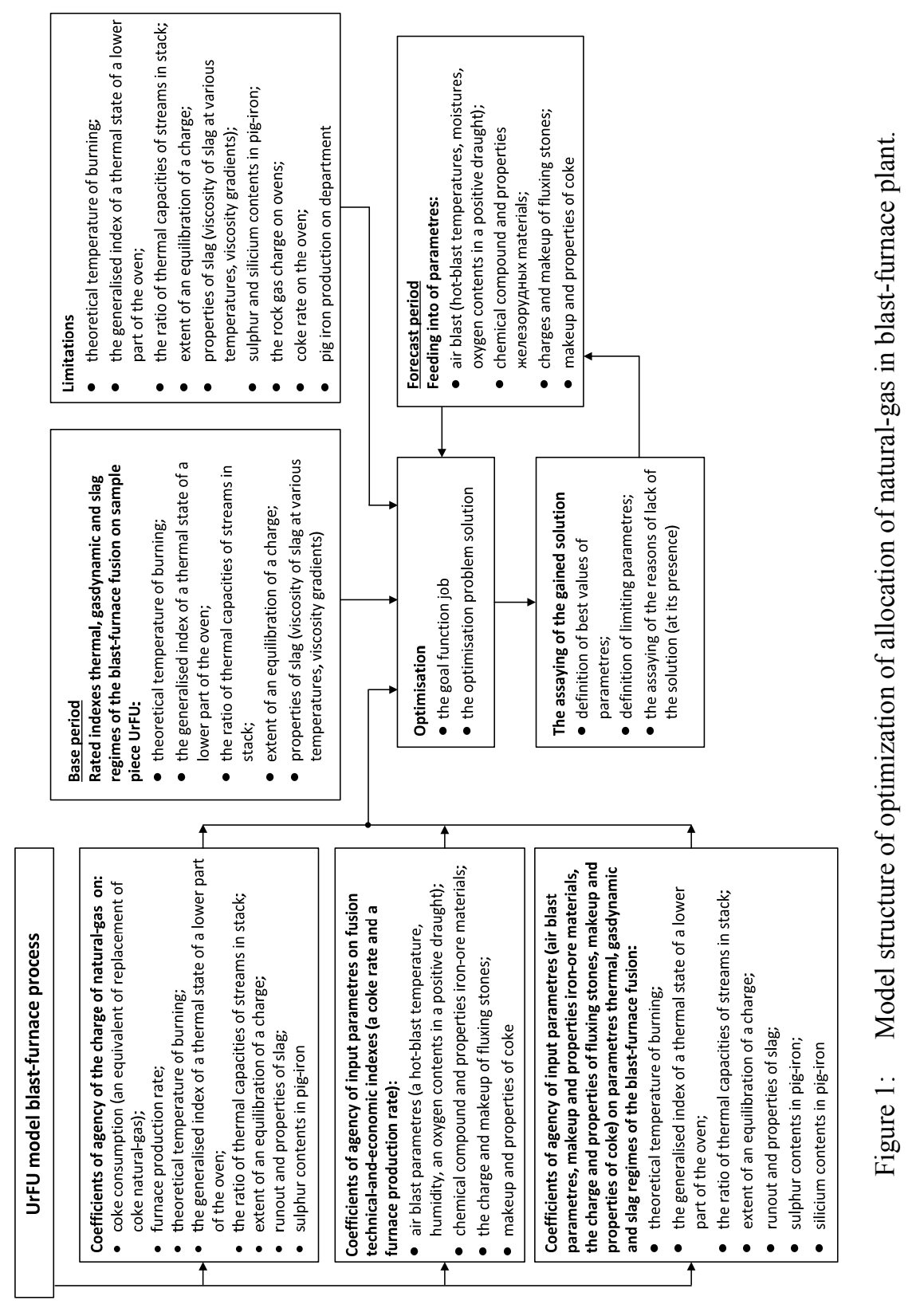


$x_{j i}^{b}$ - magnitude of parameter ${ }^{x_{i}}$ on $j$ th oven in base period;

$k_{x_{j i}}^{b}$ - a transfer ratio (adjustment coefficient) on $j$ th oven on $i$ channel of the affecting, defined on the model of blast-furnace fusion by results of operation of an appropriate blast furnace in a base period $[1,2,6,7]$.

In a general view value of parameters of the blast-furnace fusion in forecast period is defined by an additivity rule:

$$
y_{j}^{f}=\sum \Delta y_{j i}+y_{j}^{b},
$$

where $\sum \Delta y_{j i}$ - the sum of modifications of parameter $y$, the various parameters called by modifications $x$ on $i$ th oven; $y_{j}^{b}$-value of $j$ th parameter $y$ in a base period. Limitations on values of parameters provide the job:

- theoretical temperature of burning on lances $T_{j},{ }^{\circ} \mathrm{C}: T_{j}^{\min } \leq T_{j} \leq T_{j}^{\max }$;

- generalised index of a thermal state of a lower part of furnace $Q_{b, i}$, MJoule/ton pig-iron: $Q_{b, j}^{\min } \leq Q_{b, j} \leq Q_{b, j}^{\max }$;

- Ratios of thermal capacities of streams of a charge and gases in stack $m_{j}$, share units: $m_{j}^{\min } \leq m_{j} \leq m_{j}^{\max }$;

- Extents of an equilibration of a charge gas stream $C y_{j}$, share units: $C y_{j}^{\min } \leq C y_{j} \leq C y_{j}^{\max }$

- Properties of slag:

- Viscosities of slag at the set outlet temperature $\left(\eta_{\mathrm{sl}}\right), 1400^{\circ} \mathrm{C}-$

$$
\begin{aligned}
& \left(\eta_{\mathrm{sl}}^{1400}\right), \quad 1500^{\circ} \mathrm{C} \quad-\quad\left(\eta_{\mathrm{sl}}^{1500}\right): \quad \eta_{\mathrm{sl}}^{\min } \leq \eta_{\mathrm{sl}} \leq \eta_{\mathrm{sl}}^{\max } ; \\
& \eta_{\mathrm{sl}}^{1400 \min } \leq \eta_{\mathrm{sl}}^{1400} \leq \eta_{\mathrm{sl}}^{1400 \max } ; \eta_{\mathrm{sl}}^{1500 \min } \leq \eta_{\mathrm{sl}}^{1500} \leq \eta_{\mathrm{sl}}^{1500 \max } ;
\end{aligned}
$$

- Gradients of viscosity of slag $\Delta \eta_{0.7}^{2.5}$ and $\Delta \eta_{1400}^{1500}: \Delta \eta_{0.7}^{2.5}$ - shows how much sweepingly slag gets sluggish in the field of the downgraded temperatures ("short" or "long" slag) and numerically it is equal to a modification of viscosity of slag at magnification of temperature of slag on $1{ }^{\circ} \mathrm{C}$ over the range to viscosity of slag from $2.5 \mathrm{~Pa} \cdot \mathrm{s}(25 \mathrm{P})$ to 0.7 Pa.s (7 P): $\Delta \eta_{0.7}^{\min 2.5} \leq \Delta \eta_{0.7}^{2.5} \leq \Delta \eta_{0.7}^{\max , 2.5} ; \Delta \eta_{1400}^{1500}-$ shows slag in the field of finite (working) temperatures, numerically equal a modification of viscosity of slag on $1^{\circ} \mathrm{C}$ within $1400-1500^{\circ} \mathrm{C}$ is how much resistant to: $\Delta \eta_{1400}^{\min , 1500} \leq \Delta \eta_{1400}^{1500} \leq \Delta \eta_{1400}^{\max , 1500}$;

- Contents of sulfur $\left[S_{j}\right]$ and silicium $\left[S i_{j}\right]$ in pig-iron, \%: $\left[S_{j}^{\min }\right] \leq\left[S_{j}\right] \leq\left[S_{j}^{\max }\right] ;\left[S i_{j}^{\min }\right] \leq\left[S i_{j}\right] \leq\left[S i_{j}^{\max }\right]$. 
- The natural-gas consumption by furnaces $V_{j}^{N G}, \mathrm{~m}^{3} /$ hour:

$$
V_{j}^{N G, \max } \leq V_{j}^{N G} \leq V_{j}^{N G, \min } .
$$

Limitations on blast-furnace plant provide the job:

- summarised coke rate on blast-furnace plant $G_{\Sigma}^{C}$, tons/hour:

$$
G_{\Sigma}^{C, \min } \leq G_{\Sigma}^{C} \leq G_{\Sigma}^{C, \max } .
$$

- $\quad$ set pig iron production on blast-furnace plant $G_{\Sigma}^{I r}$, tons/hour: $G_{\Sigma}^{I r, \min } \leq G_{\Sigma}^{I r} \leq G_{\Sigma}^{I r, \max }$.

- the common charge of natural-gas on plant $V_{\Sigma}^{N G}, \mathrm{~m}^{3} /$ hour: $V_{\Sigma}^{N G, \min } \leq V_{\Sigma}^{N G} \leq V_{\Sigma}^{N G, \max }$.

Maximum permissible values of magnitudes, i.e. numerical value of parameters, are defined by a method of mathematical modelling, and in the absence of such possibility - a method of expert estimations that allows to realise model customisation on real process including through formalization of experience of technical and technological staff [1, 2].

Block «Optimization» includes:

- Specify of goal function. The mathematical model of optimal allocation of natural-gas in blast-furnace plant contains the linear goal function in a general view and limitation. The goal function leads to maximum effectiveness of usage of natural-gas in plant:

$$
Z=\sum_{j=1}^{n}\left\{\alpha\left(e_{j} C_{C}-C_{N G}\right)+(1-\alpha) C_{P}\left[\Delta P_{j}^{N G}-e_{j} \Delta P_{j}^{K}\right]\right\} V_{j}^{N G} \rightarrow \max
$$

where $Z$ - effectiveness of usage of natural-gas in department, rubles/hour; $n-$ number of furnaces in plant; $\alpha$ - weight coefficient, which defines what is more preferable - scoring money terms or scoring productivity, $0<\alpha \leq 1 ; e_{j}-$ coke replacement equivalent on natural-gas, $\mathrm{kg}$ coke $/ \mathrm{m}^{3}$ natural-gas; $C_{C}-$ coke cost, rubles/kg coke; $C_{N G}$ - natural-gas cost, rubles $/ \mathrm{m}^{3} ; C_{P}$ - conditionally constant coefficient, which shows on how many expenditures increase at productivity magnification, rubles/ton pig-iron; $\Delta P_{j}^{N G}$ - productivity modification $j$ furnace at magnification of the charge of natural-gas on $1 \mathrm{~m}^{3}$, ton pig-iron $/ \mathrm{m}^{3}$ naturalgas; $\Delta P_{j}^{C}$ - productivity modification $j$ furnace at coke rate magnification on 1 $\mathrm{kg}$, ton pig-iron/kg coke; $V_{j}^{N G}$ - natural-gas consumption on $j$ furnace, $\mathrm{m}^{3} /$ hour;

- The optimization problem solution.

The block «Assaying of the gained solution» includes:

- Calculation of best values of the charge of natural-gas gas on furnaces and parameters of operation of separate furnaces and blast-furnace plant generally in design phase; 
- Definition of aspects and values of limiting parameters.

Performance of the assaying of the reasons of lack of the solution (at its lack).

\section{Informational-modelling system}

On the presented model the informational-modelling system optimization of allocation of natural-gas in blast-furnace plant was developed (figure 2). It includes following units: feeding into and correction of data; treatments of an input information; calculation module; optimization; output and the assaying of results.

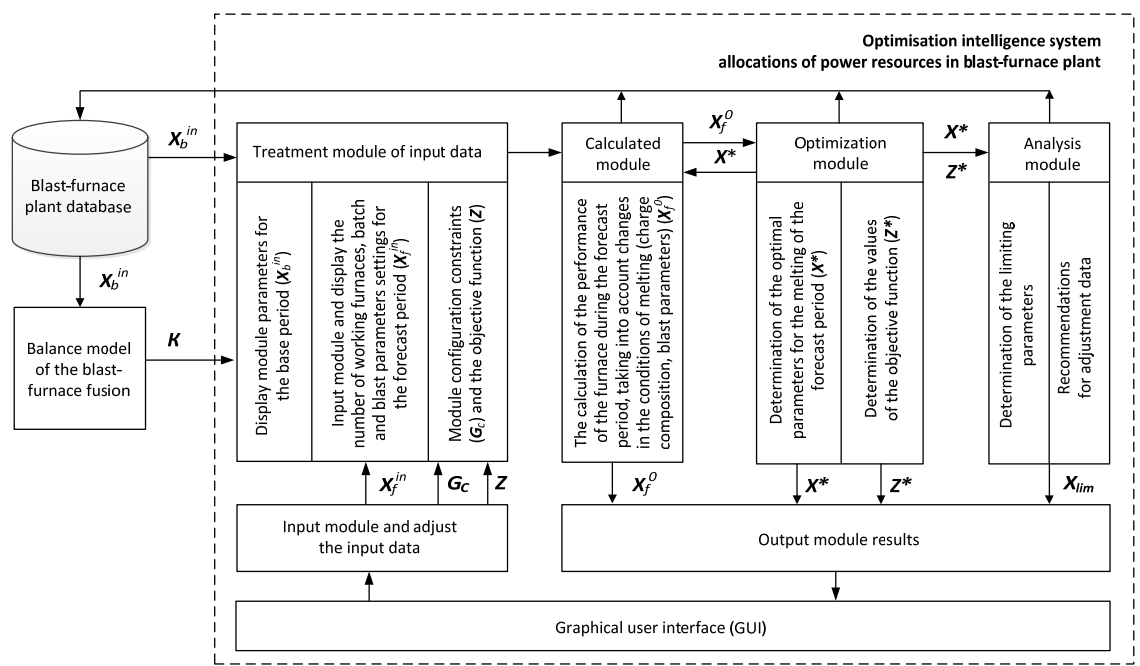

Figure 2: Intelligence system structure of optimization of allocation of naturalgas gas: $X_{b}^{i n}-$ input parameters vector for a base period; $K-$ adjustment coefficients vector; $X_{f}^{i n}-$ input parameters vector for the forecast period; $X_{b}^{0}$ - counted parameters vector for the base period; $X_{f}^{0}$ - counted parameters vector for the forecast period; $X^{*}$ - a vector of best values of parameters; $Z^{*}$ - value of the goal function.

In figure 3 outcomes of the comparative assaying of allocation of natural-gas on the basis of data of operation of blast-furnace plant of OJSC "Magnitogorsk Iron and Steel Works" are presented. The assaying of outcomes shows, that the optimization model of joint distribution of natural-gas and oxygen allows to use effectively available fuel and energy resources taking into account technological limitations on operation of separate furnaces and blast-furnace plant generally. 


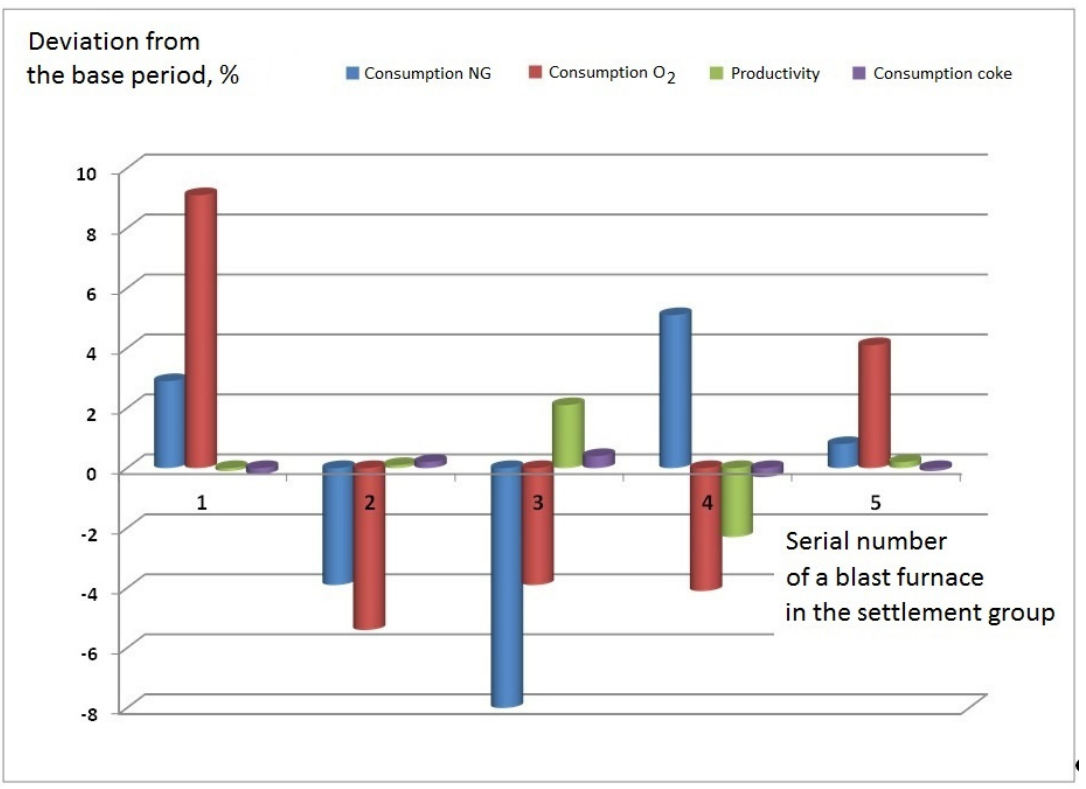

Figure 3: $\quad$ Outcomes of the comparative assaying of allocation of naturalgas in group of blast furnaces.

\section{Conclusion}

Usage of the developed unit in modern informational-modelling system of an automatic control system (ACS) of the blast-furnace allows to solve operative problems of blast-furnace melting techniques, ensuring the rise of effectiveness of a decision made by technical staff in the conditions of modifications of size of fuel and energy resources (in the conditions of changes of fuel characteristics and availability of energy resources), instability of composition and quality of ironore materials and market condition.

\section{References}

[1] Computer simulation methods of a blast-furnace smelting operation, O. P. Onorin, N. A. Spirin, V. L. Terentiyev et al. Ed. by N. A. Spirin. Ekaterinburg: UGTU-UPI, 2005. 301 pp.

[2] Modelling decision support systems in automated process control system of the blast-furnace fusion, N. A. Spirin, V. V. Lavrov, V. Y. Ribolovlev et al. Ed. by N. A. Spirin. Ekaterinburg: UrFU, 2011. 456 pp.

[3] Optimization and identification of master schedules in metallurgy, N. A. Spirin, V. V. Lavrov, S. I. Parshakov et al. Ed. by N. A. Spirin. Ekaterinburg: UGTU-UPI, 2006. 307 pp. 
[4] Optimization of allocation of natural-gas in blast-furnace plant MMK, N. A. Spirin, Y. N. Ovtchinnikov, I. E. Kosatchenko et al., Steel. 1991. № 8. pp. 13-18.

[5] The theory and forecasting practice in control systems, S. V. Emeliyanov, S. K. Korovin, L. P. Mishlayev et al. M.: Publishing join (Russian universities), 2008. 487 pp.

[6] Development and a heading mathematical and the software for flexible technological operating modes of blast furnaces, S. A. Zagajnov, O. P. Onorin, L. Y. Gileva et al., Steel. 2000. № 9. pp. 12-15.

[7] Mathematical model of the blast-furnace process, S. A. Zagajnov, O. P. Onorin, N. A. Spirin, Y. G. Yaroshenko, Steel in Translation. 2003. T. 33. № 12. pp. 1-5.

[8] Selecting the optimal natural-gas and oxygen distribution in blast furnaces by means of a model, V. V. Lavrov, I. A. Babin, N. A. Spirin, Steel in Translation. 2007. Vol. 37, No. 12. pp. 998-1001. 